\title{
LA IDENTIDAD SOCIAL EN HABERMAS: ENTRE EL CONSENSO Y LA ALTERIDAD
}

\begin{abstract}
1 renovado propósito de una reflexión sobre la modernidad en relación al presente, ha tenido que comenzar por enmarcar sus análisis en las coordenadas de una pluralidad de valores como formas de ver y entender la vida. Cuando el problema se aboca al terreno de la ética, la tematización de la identidad se convierte en un dilema privado, íntimo, individual. Cuando se trata de política entonces se convierte en público, en social, en el de una consciencia ciudadana. Ética y política confluyen cuando, como en el caso de Habermas, la discusión con la modernidad, con sus resultados o incapacidades, ha obligado a proponer como esencial la rehabilitación de una racionalidad práctica. En el momento actual, los ideales de vida humana y de felicidad son plurales y no existen nexos argumentales afines; por ello, la pluralidad de los fines, muchas veces antagónicos, igual que las diversas concepciones de la naturaleza y de la condición humana (como de sus necesidades), promueven luego actitudes emotivistas, irracionales y hasta trágicamente irónicas. ${ }^{1}$

En medio de la reflexión histórica, entre una tarea de recuperación de la memoria y una necesidad de articularla con una perspectiva crítica que movilice y otorgue sentido a la vida, el diagnóstico del presente no puede pasar sin entrar antes a una revisión de las limitaciones y aporías que sobrevienen cuando se piensa en la identidad humana como problema privado solamente. La modernidad como proyecto no acabado, necesariamente revisable, debe prestarse a tematizar sobre estas omisiones que representaron los momentos agazapados de una irresuelta articulación del mismo proyecto de la modernidad. Con la recuperación
\end{abstract}

${ }^{1}$ Richard Rorty, por ejemplo, aboga por un individualismo que, llevado hasta sus últimas consecuencias como romanticismo, no reconoce más que la necesidad de una política para tecnócratas y la moral como privada. Véase Irony, contingency and solidarity, Cambridge University Press, 1989. 
específica que Habermas hace de los nexos narrativos de la historia de la modernidad, como distorsión y supresión de una concepción particular de entender la naturaleza humana y social, el proceso de reflexión crítica sobre ella es el de una derrota que puntualiza los acercamientos narrativos a los sistemas de argumentación, según los cuales, aportar una razón es, en parte, contar la historia de lo ocurrido.

El momento crucial en la tematización de una posible identidad es el de la escisión entre hombre público y hombre privado. En el centro de este sentido de la vida bifurcada se han originado las más importantes reflexiones contemporáneas de nuestro tiempo. Hegel dio a la identidad el sentido de una lucha por el reconocimiento, movimiento que llevaba a encontrar lo igual y lo distinto, la alteridad y la mismidad en una dialéctica de identidad entre diferentes. ${ }^{2}$ Esa lucha formaba parte, a su vez, del reconocimiento explícito y falible de la coexistencia entre los hombres (la eticidad).

Mientras tanto, los espacios de reconocimiento de lo social se han ido desvinculando de los proyectos individuales de vida, de lo que hacemos y lo que somos. En el vórtice de estos dilemas están las convergencias indispensables entre la política y la moral, entre una filosofía política normativa y un discurso ético.

Empezar por el reconocimiento del otro implica la aceptación del diálogo. La comunicación es el único reducto que se opone a la soledad y al aislamiento. Comprender, en este sentido, significa hacer visible los espacios íntimos de configuración del yo (aun cuando existan espacios intraducibles). Cuando esta tarea se hace reflexiva se ejerce la identidad que involucra un concepto central a toda temática social: el de intersubjetividad. La forma específica en que una sociedad articula todos los niveles de vida cotidiana (cultura, creencias, tradiciones, valores y momentos históricos) constituyen el conjunto único e irrepetible del que somos parte, en tanto que biografía, en tanto que historia de vida, en tanto que hombres particulares. La forma en cómo se erige esta intersubjetividad estructurando unos niveles que sobresalen sobre otros, tejiendo institucionalmente unas valoraciones sobre otras, relacionando las necesidades con las condiciones mismas de vida, son también una parte constitutiva de la racionalidad práctica.

Por eso, el que hoy se vuelva a hablar con insistencia de la

${ }^{2}$ Hegel, W. F. G., «La dialética del amo y del esclavo», en La fenomenología del espíritu, Ed. F. de C. E., México, 1960. 
necesaria relación entre ética y política nos devuelve a un plano que aparecía como irremediablemente perdido. Ni los discursos científicos, ni religión alguna son capaces de salvarnos de la finitud y fragilidad que acusamos como síndrome de nuestra época. No existe más que una posibilidad de reconocimiento mutuo y una necesidad de construcción de lo que somos y queremos hacer que sea capaz de otorgar un nexo vital con un mundo propio y compartido. La identidad social es moral porque es la única que se cuestiona sobre lo que somos.

«Se trata de una elección racional de los medios ante fines dados o de la ponderación racional de los fines ante preferencias existentes. Nuestra voluntad está ya fácticamente determinada por deseos y valores; determinaciones ulteriores sólo se realizan en atención a alternativas en la elección de medios o bien en la fijación de fines (Zielsetsung)». ${ }^{3}$

Habermas ha intentado una articulación del proyecto constructivo de una identidad social como intersubjetividad en donde ética y política se entrecruzan. La categoría que articula estas dimensiones de la vida social es la formación racional de la voluntad. Por ello, el presente trabajo tiene la intención de reflexionar sobre estas cuestiones indagando acerca de la posibilidad de plantear que, en el terreno ético y político, debe tener un puente que se trace desde la filosofía de la acción. El concepto que pretendo introducir para este vínculo es el de phrónesis (tomado de Aristóteles, reconfigurado luego por Gadamer y con las nuevas ideas que a él, le introduce Alessandro Ferrara). La phrónesis como competencia social puede permitirle a Habermas una salida frente a la pluralidad de normas y valores con que tiende a enfrentarse cada vez que propone su esquema formativo de la voluntad racional como construcción de una identidad social.

\section{I. Ética y política como terreno propicio del concepto de intersubjetividad}

Habermas articula su proyecto de rehabilitación de la racionalidad práctica como una reivindicación de la modernidad.

\footnotetext{
${ }^{3}$ Habermas, J., «Acerca del uso ético, pragmático y moral de la razón práctica», conferencia leída durante el simposium sobre Habermas realizado en México durante su visita en septiembre de 1989, pág. 4.
} 
Pero no de cómo ha podido ser sino de cómo no ha sido, es decir, contrafácticamente. Para ello, es necesario promover un reencuentro entre la ética y la política a un nivel orgánico, de constitución social de la colectividad específica de la que somos parte. En el terreno político existe un espacio constitutivo de colectividades identificantes que se vale de componentes simbólicos de solidaridad, ritualidad y teatralidad. La identidad es un imperativo auto-constitutivo en el nivel de lo social que se refuerza solamente cuando está interconectado con el terreno de la moral, de una reflexión normativa que permite cuestionarnos sobre el proyecto de vida por el que apostamos.

Habermas piensa en su esquema de intersubjetividad como el terreno propicio para la comunicación, como el ejercicio necesario de la comunicación y la reflexión y, en tanto que tal, como procedimental. Habermas recupera la noción ilustrada de voluntad, pero no como una voluntad rousseaunianamente general, sino como espacio comunicativo y reflexivo de igualdad ciudadana (Fröbel) que, como formación colectivo-reflexiva de la consciencia política es capaz de articular la comunicación como un saber y competencia, cuyo mejor impulso, son las argumentaciones no coactivas. Tal propuesta teórica se beneficia de la teoría social y es por ello que Habermas se ha vinculado cada vez más a procedimientos hermenéuticos y pragmáticos.

«A diferencia de Rousseau, que ve una conexión natural entre razón práctica y la voluntad soberana de una colectividad -la simple forma de ley general- Fröbel la ve sustentada en un procedimiento de formación de opinión y voluntad que estipula cuándo es posible sospechar que una voluntad -no una razón- política tiene razón». ${ }^{4}$

Cuando Habermas recurre a la hermenéutica, tiene ya en mente el vínculo específico que la formación de la voluntad política tiene con los elementos comprensivos y de sentido y, más aún, de lo que puede ser el potencial de una autorreflexión crítica. ${ }^{5}$ Pero la hermenéutica sola, con el único apoyo de los procedimientos hermenéuticos no puede situarse como crítica y, por ello, sólo es posible si se la relaciona con un modo de explicación

\footnotetext{
${ }^{4}$ Habermas, J., «Soberanía popular como procedimiento», conferencia dictada en México por el doctor Habermas en el simposium que con motivo de su visita se realizó en septiembre de 1989, pág. 21.

${ }^{5}$ Véase debate Habermas-Gadamer, en La lógica de las ciencias sociales, Ed. Tecnos, trad. Jiménez Redondo.
} 
causal cuyos referentes empíricos y categorías abstractas permitan interpretar las patologías de la modernidad. Es por eso que Habermas llega a la hermenéutica a través de las consideraciones sobre la relación entre el lenguaje y la acción que ha posibilitado la comprensión de su vínculo indisoluble. Cuando polemiza con Gadamer, Habermas traspasa el umbral de la lingüística y con ello, enfrenta a la pragmática como el siguiente paso teórico. La pragmática correlaciona directamente al lenguaje en uso con sus contextos. Ambos precisan el sentido y la interacción entre los distintos niveles en los que nuestra realidad se encuentra tejida. La teoría crítica es la mediadora entre las explicaciones causales y la comprensión de sentido. Ella es el ejercicio radical de Ilustración, en tanto que impone prácticas de acción y reflexión que constituyen la actividad política de los grupos sociales, así como las argumentadas orientaciones sobre la acción que ellos decidan.

El puente que se establece entre una racionalidad teórica y otra práctica es el de la voluntad política como ejercicio reflexivo y de sentido que da a la identidad intersubjetiva de un grupo social una estructura, un proyecto ético-político.

Habermas piensa que volviendo al concepto de ilustración, entendiendo con ello la autorreflexión crítica como conocimiento, es posible constituir una voluntad política que luego será racional y que es la única capaz de indagar sobre el sentido de la acción, de los deseos, de los valores y de su articulación e institucionalización como formas de vida.

«No deja de ser sintomática que, según los criterios de racionalidad tecnológica no pueda alcanzarse nunca un acuerdo sobre un sistema colectivo de valores por la vía de una discusión ilustrada en el espacio público-político, es decir, a través de un acuerdo alcanzado racionalmente, sino sólo por la suma o compromiso los valores están en principio fuera de toda discusión». ${ }^{6}$

En la medida en que la forma comunicativa de organizar la práctica queda sustituida por una «auto-estabilización cuasi-instintiva de los sistemas sociales», desaparece ese proceso de autoilustración política que debe ejercer la ciudadanía como voluntad política. La configuración de ella requiere, no sólo de una información adecuada (politización), sino de la posibilidad de auto-constituirse como una reflexión colectiva que implique valoración,

${ }^{6}$ Habermas, J., Theorie und Praxis, hay trad. por Tecnos, Madrid, 1987, pág. 307. 
discusión y argumentación en torno a las consecuencias de toda índole que atañen a los diversos medios para conseguir ciertos fines. Cuando reflexionamos sobre lo que hacemos y deseamos realizar erigimos la identidad moral. ${ }^{7}$ Una recuperación de la voluntad política capaz de someter a crítica tanto a las prácticas de una racionalidad instrumental como a las reflexiones normativas y expresivas de lo social es el único camino para recuperar las máximas de la ilustración.

La máxima de la ilustración, según la cual, la toma de decisiones se convierte en una discusión pública que no tiene coerciones de ninguna especie y que reconoce la necesidad de participación de todos los que conforman el colectivo social es el objetivo habermasiano que prima en toda su obra.

A partir de La teoría de la Acción Comunicativa Habermas reformula su concepto de formación de la voluntad política en el de formación racional de la voluntad. Habermas utiliza a la pragmática como una herramienta reconstructiva de la forma en la que intuitivamente aprendemos a hacer uso del lenguaje para comunicarnos. El contexto y el sentido articulados enmarcan la configuración social que se delimita en cada intersubjetividad, y en base a su posible reconstrucción, se erige la crítica y contrastación con lo que se considera como racional en tanto que comunicación. La formación de la voluntad racional es mediadora entre procesos históricos concretos y se apoya en esquemas reconstructivos de lo que se considera una racionalidad comunicativa.

De esta forma, la teoría de Habermas encuentra un concepto de intersubjetividad en cuyos espacios ético-políticos queda estructurada la proyección y discusión de los fundamentos e ideales normativos. Es en la intersubjetividad en donde se deben hallar los cimientos de la identidad social, del filtro social en el que recae cada individualidad. El esfuerzo habermasiano por construir un modelo mediador entre el individuo y el grupo social se constata con su idea de intersubjetividad como el espacio compartido en el que se configura la formación racional de la voluntad. Habermas considera que todas las cuestiones de opinión son parte de la intersubjetividad y que, por tanto, la escisión entre

${ }^{7}$ Autores como Charles Taylor y Carlos Thiebaut han estado trabajando sobre el concepto de identidad moral de la modernidad: véase Taylor. Ch., Sources of the self. The making of modern Identity, Harvard U. Press, 1989; Thiebaut, C., El arte del nombrar, próximo a publicarse en la editorial La Balsa de Medusa. 
hombre público y hombre privado pone en entredicho el sustrato fuerte que sostienen los ideales ilustrados, aquel en el cual el saber es intersubjetivamente compartido por todos. A esto responde su preocupación por la formación racional de la voluntad que requiere de mecanismos interconectados con la acción política pero que, para hacerlos factibles, deben hacer uso también de la reflexión moral conjunta. Es necesario, pues, combatir la colonización de los mundos de vida. Ello significa que debe encontrarse un camino a través de la teoría social (la hermenéutica y la pragmática como herramientas de la teoría de la acción comunicativa) que suplante a la filosofía. El camino de la racionalidad es aquel en el que pueden abrirse hacia un diálogo todas las cuestiones que pertenecen a las distintas esferas del saber que son compartidas en la intersubjetividad (verdad, rectitud y sinceridad).

Pero Habermas va más lejos tratando de combatir a los demonios plurales de Weber.

Pretende, en su reconstrucción, dejar asentado que sus conceptos como el de moralidad universal o legalidad, que han fructificado en algunas prácticas concretas de la democracia contemporánea, son formas que la ilustración ha ganado como formas racionales. Son parte de un proceso de aprendizaje colectivo que, mediante acciones y prácticas, ha ocupado el territorio de la intersubjetividad.

El núcleo de la concepción habermasiana de la identidad colectiva como intersubjetividad lo ha tomado de Durkheim. La autoridad moral de las normas sociales tiene su anclaje en lo religioso. En la intersubjetividad, el consenso normativo es mediado de una forma simbólica por todo lo que promueve culturalmente una identidad colectiva. La modernidad inaugura la «lingüistización de lo sagrado».

«El simbolismo religioso representa una de las tres raíces prelingüísticas de la acción comunicativa; pero sólo a través de la acción comunicativa pueden ramificarse las energías de la solidaridad social ligadas al simbolismo religioso y como autoridad moral, lo mismo a las instituciones que a las personas. ${ }^{8}$

Así las funciones de la práctica religiosa pasan a convertirse en parte de la acción comunicativa. Por tanto, los fenómenos que pertenecen al mundo de la vida tales como la reproducción cultural, la integración social y el desarrollo de la personalidad,

\footnotetext{
${ }^{8}$ Habermas, J., Theorie des kommunikativen Handelns, tomo II, pág. 93.
} 
son parte del proyecto de racionalización como comunicación o como razón comunicativa. La intersubjetividad es, por tanto, el núcleo de la identidad colectiva entretejida con la individual.

\section{La identidad entre diferentes en la pluralidad de mundos de vida}

Cuando Habermas construye su esquema del diálogo ideal de la comunicación como esquema contra-fáctico, proponiendo al mismo tiempo que lo constitutivo de la identidad social debiera ser el consenso y no la discrepancia, enfrenta un problema irresoluble en sus términos, el de la pluralidad de valores y la forma en que el acuerdo como consenso implica un grado de racionalidad. Albrecht Wellmer en Ethik und Dialog ha hecho una crítica a este criterio de racionalidad como algo imposible y, al mismo tiempo, como un criterio circular.'

Habermas se introduce en un «impasse» cuando propone la idea de racionalidad consensual en la que luego se puede dar privilegio a la decisión de la mayoría. Los ejemplos de errores históricos de decisiones en los que la mayoría ha decidido son evidentes y no son precisamente racionales. Aun para los utilitaristas el dilema del «flujo equilibrado» de todos los intereses sociales en el proceso de modernización es un problema. La única forma de salvaguardar la identidad como una «identidad entre diferentes» es potenciando las diferencias que son lo que hacen de una intersubjetividad específica algo singularmente compartido. Son los diferentes estratos valorativos y simbólicos que articulan nuestras visiones particulares de ver el mundo lo que nos permite identificarnos con otros. Pero si nuestra construcción social de la realidad es también un signo distintivo de lo que somos y hacemos, en tanto que seres concretos, entonces nuestras versiones no pueden tomarse como algo válido o verdadero

${ }^{9}$ «La teoría de la verdad consensual, tal como la han desarrollado Apel y Habermas, trata una vez más de establecer un paradigma último de validez intersubjetiva. La idea subyacente es que este parámetro de validez, en contraste con todos los parámetros particulares, criterios, o reglas, nunca podrían cuestionarse, ya que coincidirían con la noción misma de verdad. La teoría consensual podría establecer dicho paradigma, pero sólo con el precio de hacerlo inaplicable en tanto paradigma... Apel y Habermas, quienes quieren defender a la razón, tratan de mostrar que hay tales criterios, sólo que son formales o procesales.» Véase Wellmer, A., «Intersubjetividad y razón», en Racionalidad, Ed. Siglo XXI, pág. 261. 
en términos consensuales o representacionales, sino como lo que ha sido prudente creer en una situación determinada y en la que no es posible apelar a los juicios a priori. ${ }^{10}$ Pero de acuerdo a Habermas, la manera de evitar el relativismo que sobreviene cuando no se demarca claramente un criterio de racionalidad es mediante el criterio de mayor rango de racionalidad que sobreviene cuando tenemos la opción de cuestionarnos sobre el papel que tiene nuestra interpretación de los hechos. Tal visión no evade la conclusión de que el criterio de racionalidad, en el cual se acepta como rango de ella la consciencia de las diversas interpretaciones sobre la realidad, es un criterio etnocéntrico. Pero cuando nos enfrentamos a criterios en donde se trata de dos marcos éticos post-convencionales o dos formas de ver la vida post-tradicionales o incluso dos paradigmas científicos con igual número de anomalías o de aciertos, el criterio de racionalidad se diluye. Frente a esta problemática de la pluralidad de valores, se puede hablar de una identidad entre diferentes sin caer necesariamente en un relativismo absoluto al reubicar a la phrónesis como una competencia comunicativa necesaria para la construcción de la identidad social, es decir, de la valoración de la intersubjetividad que está en juego.

El concepto de juicio prudencial se constituiría como una habilidad necesaria requerida para tomar una buena decisión. Si la voluntad racional exige la capacidad de argumentación y de comunicación, entonces entramos de lleno, en lo que Habermas llama la formación racional de la voluntad. La mejor elección no podría demostrarse pero sí ser ilustrada en la misma práctica. Y ella sólo se conseguiría si se pudiera tener una consciencia cabal de la fragilidad de la identidad que se reconstituye a cada paso, tras reflexiones, tras deliberaciones, tras una construcción comprometida de la necesidad de rearticular lo que debe primar sobre lo que no y con un reconocimiento de la fuerza de la movilidad social (con sus distintos llamados a la solidaridad que requieren los distintos grupos en particular). Ello implica reconocer que lo que nos hace identificarnos es la necesidad del reconocimiento de los otros. Alessandro Pizzorno lo ha expresado como una crítica al individualismo metodológico, tan en boga en nuestros días: «Detrás de la autonomía es necesario algún otro yo que la reconozca».

\footnotetext{
${ }^{10}$ Esta concepción prudencial sobre la realidad es una interpretación pragmatista, especialmente, en la visión de John Dewey y de William James. Actualmente, teóricos como Rorty y como Alessandro Ferrara han vuelto a insistir en la necesidad de recuperar estas visiones pragmatistas.
} 
La formación racional de la voluntad exige una capacidad de argumentar y explicitar los juicios que vinculen las consideraciones dialécticas de una interacción social y que permitan que la comunicación sea un lazo de reconocimiento de la otredad y la mismidad como factores dinámicos que aseguren la identidad entre diferentes.

La competencia social que es la phrónesis se ejerce desde que el momento reflexivo hace de su racionalidad una práctica con juicios prudenciales que consideran lo menos malo como la mejor decisión, como lo que es prudente creer dada una situación determinada. ${ }^{11} \mathrm{La}$ formación de una identidad es el único proyecto que puede confirmarnos en la finitud, en la imperfección y en la fragilidad, pues una identidad nunca se acaba de lograr y, sin embargo, es una necesidad humana el luchar por conseguirlo.

«Lo que da respuesta a esta pregunta (de quién soy yo) para nosotros es un entendimiento de lo que es de crucial importancia para nosotros. Saber quién soy yo es una especie de conocimiento sobre dónde estoy situado. Mi identidad es definida por los compromisos e identificaciones que proveen el marco u horizonte en el cual yo puedo determinar de caso en caso lo que es bueno, valioso, o que debe hacerse, o con qué debo solidarizarme u oponerme. En otras palabras, es el horizonte en el cual yo soy capaz de tomar una posición». ${ }^{12}$

El juicio prudencial o phrónesis es una capacidad reflexiva que se ejercita y se practica en la acción y en la toma de decisiones, pues ella es la mediadora entre los diversos valores colectivos. Se podría decir incluso que la prudencia de creer alguna cosa y la que se decide a elegir por lo que permite una mejor aproximación al problema es la que posibilita una dimensión más profunda de la realidad. La verdad como conocimiento y necesidad estarían fuera de este esquema y, en su lugar, un nuevo concepto de corrección estaría en relación con las contingencias en las que estamos inmersos los seres humanos en nuestras acciones.

Al hablar de una identidad colectiva como un proyecto de recuperación de la intersubjetividad, volvemos a insistir que, en

${ }^{11}$ Véase Ferrara, A., «On phronesis», Revista Praxis International, invierno de 1987-88.

${ }^{12}$ Taylor, Charles, Sources of the Self. The making of the Modern Identity, Harvard University Press. Massachusetts, 1989, pág. 27. 
ella, ya no se vislumbran estructuras universales ahistóricas, sino los elementos que, dada cierta situación, resaltan más que otros. Por tanto, una visión así requeriría de la historia pero no de una reconstrucción hegeliana de los proyectos de vida racionales sino como un recuento narrativo en el que se trataría de especificar las estructuras potenciadas por las decisiones de una comunidad social, como las que en un momento dado, permitieron el máximo de posibilidades creativas e imaginables con respecto a su proyección y potencialización futura.

Habermas teme a la pluralidad de valores (de los demonios que Weber siempre tuvo presentes) y por ello, rehuye el problema de la coexistencia de los mismos en un proyecto ético-político. La phrónesis como juicio prudencial es una mediadora entre los valores plurales. Las éticas cognitivistas como las de Rawls o Habermas imponen una separación precisa entre las normas y reglas en relación con la universalización de ciertos juicios morales que deben separarse de las orientaciones pluralistas de valor. La ética que sólo mira por la rectitud parece incapaz de orientar la acción y de dar cuenta de los juicios de la esfera privada. Una noción de identidad que no se nutra también del específico filtro del individuo, carece de articulación de lo que he llamado identidad entre diferentes. La posible relación entre ética y política se comprende sólo en la medida en la que lo social y lo privado intervienen en nuestra auto-constitución. Encontrar un punto de equilibrio entre ambas parece imposible si se la contempla desde esta perspectiva. No en vano el problema de la identidad y del sujeto vuelven a interesar a los teóricos sociales desde muy diversas perspectivas.

La phrónesis es indispensable para la conformación de los juicios morales en, por lo menos, cuatro aspectos:

1. En la medida en la que se debe determinar el cómo de la aplicación de normas sobre una situación concreta.

2. En tanto que uno debe decidir si una acción cumple su prescripción.

3. En la medida en que ciertas interpretaciones de una norma están enraizadas en valores competitivos que exigen una elección.

4. En la medida en que las acciones son interpretaciones de actividades y dependiendo de la interpretación que de ellas hacemos, pueden tener distintas implicaciones éticas.

Volvamos ahora al punto en el que la teoría de Habermas se enredaba con aquello del consenso como fundamento de lo racional y lo racional como el camino a seguir para el consenso.

Habermas, recuperando la idea ilustrada de voluntad general, 
toma como idea regulativa a la situación ideal de habla. La verdad de los enunciados y la corrección de las normas yacen, supuestamente, sobre un consenso racional y éste se genera a partir del modelo contrafáctico, ficticio, de la situación ideal de habla. Dicha situación debe cumplir, al menos, con cuatro requisitos: participación irrestricta, igualdad de estatus, igualdad de oportunidades para continuar o terminar un discurso e igual grado de motivaciones sinceras y cooperativas. El problema que aquí se le presenta a Habermas es que no puede ser un criterio para la evaluación racional del consenso. Porque de hecho, no existe el mínimo de claridad para saber qué es lo que, efectivamente, puede considerarse como «lo más racional». Tomemos, por ejemplo, a un grupo numeroso de personas que pueden estar discutiendo durante mucho tiempo, o al contrario, a un grupo reducido que extienda su discusión hasta límites más allá de lo imaginable. ¿Cuál de ellos puede considerarse más racional? Otros ejemplos pueden igualmente ilustrar lo que digo. Dentro de un grupo de personas que han estado discutiendo durante algún tiempo y, finalmente, llegan a un acuerdo - ¿puede considerarse racional, si entre ellas existen posiciones asimétricas? $\mathrm{O}$, en un caso contrario, supongamos que tenemos a un grupo de gente que ha utilizado sus posibilidades de intervenir en una discusión con entera libertad pero que, internamente, tienen deseos de manipular a su interlocutor-, ¿podría considerarse como algo racional?

Una posible solución sería el considerar como criterio de mayor racionalidad al que se genera en las situaciones concretas que implica reconocer qué combinación específica de factores representa la mejor aproximación a la situación ideal de habla.

El universalismo habermasiano considerado como formal o procedimental se erige como un criterio de evaluación de complejos simbólicos que se argumentan como presuposiciones derivadas de un análisis pragmático del habla, que ya no puede evadir el reconocimiento de la pluralidad de formas de vida. Habermas en La Teoría de la Acción Comunicativa ha denominado racional al criterio que puede establecerse sobre la posibilidad de entender cómo interpretamos la realidad y la interpretación que más elementos de contrastación tiene aparece como la más racional. Cuando hace esta clasificación hegeliana de racionalidad con respecto a culturas distintas reconoce su carácter etnocéntrico. Pero cuando se enfrentan dos culturas distintas postindustriales, o dos teorías éticas post-convencionales o dos paradigmas científicos, ya no parece tan fácil resolver cuál de ellos es más racional. Porque un criterio de la satisfacción de 
presuposiciones de la argumentación no puede orientar la elección entre dos complejos simbólicos competitivos. Sólo un concepto como el de phrónesis puede rescatar a esta opción de un fundamentalismo metafísico.

El concepto de phrónesis tal y como lo ha trabajado Alessandro Ferrara, ${ }^{13}$ sustrae al concepto de su carácter estrictamente ético para darle una cualidad de competencia general, de «know how» o saber intuitivo, que se configura como un juicio necesario que permite una elección entre complejos de problemas interesquemáticos, transparadigmáticos o transculturales. Y en vez de plantear con tal concepto la base de un universalismo o principio de generalización, se podría intentar situarlo como una vía estimulante para la investigación específica que es inherente al juicio prudencial en sí mismo.

Ferrara define a la phrónesis así: «Es la competencia para elegir entre dos esquemas conceptuales que implican valorizaciones distintas e incompatibles en las que no se puede invocar a criterios a priori». ${ }^{14}$

Vista así, la capacidad de ejercer este juicio prudencial en la investigación científica potenciaría la designación de elegir entre dos paradigmas rivales o programas de investigación competitivos que tienen números semejantes de anomalías o de beneficios. En un terreno ético, la phrónesis designaría la habilidad moral del actor para preferir entre distintas orientaciones de valor en conflicto que, normalmente, comportan diferentes modos de vida. Pero para el esquema habermasiano podría tomarse como la habilidad del actor para evaluar el consenso racional y qué factores de la situación ideal de habla se acercan más al tipo ideal como una conjunción de posibilidades. En la medida en que reflexionamos sobre las diferencias cualitivas y sobre nuestras decisiones como algo determinante de ellas, el concepto de intersubjetividad como identidad social adquiere una configuración real. ${ }^{15}$

La prioridad de valores, qué valores pueden ser más importantes que otros, así como las necesidades humanas básicas que una sociedad requiere no pueden responder con el argumento de unos universales dados a priori. Porque la relación de ellos, la prioridad de unos valores sobre otros, de una forma de vida, de

\footnotetext{
${ }^{13}$ Ferrara, Alessandro, «On phronesis», en Revista Praxis International, invierno de 1987-88.

${ }^{14}$ Ibid, op. cit.

${ }^{15}$ Así lo tratan en sus libros Charles Taylor, Carlos Thiebaut y Alessandro Ferrara.
} 
una manera de entender el mundo son la configuración específica que nosotros le otorgamos cuando decidimos sobre el proyecto de vida por el que apostamos. Lo que se erige como una identidad cultural concreta es el equilibrio de los factores que la componen y la hacen única. A esto, Stephen Toulmin lo llama «ecología intelectual». ${ }^{16}$ La cuestión entonces vendría a ser algo así como: ¿cómo realizamos un juicio acerca de la integridad de una posible identidad? Las necesidades han de verse con lo necesario, los valores deben formar parte de una estructura mucho más compleja que las formas institucionalizadas como patrones generales. Así lo expresa Ferrara cuando dice que:

«La dignidad del ser humano, su valiosa existencia, o alguna noción semejante compartida es el punto determinante de por qué necesitamos lo que necesitamos y valoramos lo que valoramos». ${ }^{17}$

Esta noción interrelacionada entre valores y necesidades tiene que ver con lo que podemos llamar la identidad intersubjetiva. En ella se pone en juego nuestra percepción de continuidad, la configuración de nuestras urgencias y un proyecto ideal de lo que virtualmente queremos ser y hacer. Dewey contemplaba en su pragmatismo esta interacción entre acción e imaginación con el núcleo vital de nuestros deseos e intenciones ligados a una realidad concreta. Todo lo que no se vincule a las varias instancias que ella comporta queda como un mero producto de la fantasía o a lo sumo, de la ideología.

La identidad individual se concibe de acuerdo a las necesidades vinculadas con nuestra interiorización del mundo externo y social, con la autoestima y la capacidad de orientarnos dentro de la interacción social de acuerdo a nuestros valores delimitados por ella. La identidad colectiva contempla también la reproducción cultural, la integración y socialización como factores clave para la transmisión, reproducción y mantenimiento de los valores.

El equilibrio entre necesidades y valores es la misma capacidad de ejercer un juicio que permite una relación especial con la imaginación con el objetivo de crear una identidad equilibrada y cohesionada. La phrónesis es una habilidad de crear cursos de acción y de asignar prioridades a los valores de forma tal que resulten auténticos y opuestos a la perpetua teatralidad. La capacidad

16 Toulmin, Stephen, On human understanding, hay traducción al castellano en Alianza Universidad, Madrid, 1979.

\footnotetext{
${ }^{17}$ Ferrara, A., «On phronesis».
} 
de reconocer qué necesidades son cruciales para el equilibrio de una identidad no puede ser la misma que la capacidad de lograr una autorrealización efectiva, aun cuando constituya una condición para ello. Lo que en suma debe ser reconocible para ejercer un juicio prudencial es lo auténtico, ello permite la integridad de un actor, su recuperación es la autenticidad.

El verdadero proyecto humano involucra una noción de poder hacer las cosas bien, en la excelencia. La Eudaimonia de Aristóteles tendría que convertirse en una teoría de la identidad como lo han señalado varios autores. ${ }^{18}$ Mantener, en este sentido, la identidad, sería encontrarle cohesión a nuestra actuación en una pluralidad de situaciones. Actuar bien, quiere decir tomar los retos que la propia identidad promueve como una parte específica de la biografía de la que nos apropiamos. En el curso de la vida, uno es capaz de enriquecer la trama narrativa con una cantidad de episodios y etapas compatibles con la finitud, lo fragmentario, como una dialéctica entre esos fragmentos diferentes que nos constituyen como un ser único e irrepetible. La habilidad de unificar estos momentos de la vida y la biografía de la que somos parte, como una narración coherente, es el bien que Aristóteles denominaba Eudaimonia.

El objetivo de ella no es otro que sí misma. Es un rasgo de carácter que se expresa en la acción como ingrediente esencial de una forma de vida, la que conduce a la Eudaimonia. Y ya que ninguna virtud puede ejercerse a menos que uno sea capaz de apreciar cómo las diferentes situaciones confieren distintos significados a nuestros actos, la phrónesis nos proporcionaría un ordenamiento de los diversos bienes que requiere nuestra vida. Y, por ello, no puede ser universalmente a priori, sino que su justificación es su particularidad y su consciencia es la adquisición de la identidad.

Con la phrónesis se evitaría caer en discursos abstractos y podría articularse como un procedimiento deliberativo, constitutivo de cualquier voluntad política e intersubjetiva que exige una normatividad como forma particular de salvaguardar la identidad. Un proyecto dialógico que cimentara su fuerza en lo que considera su conexión de necesidades y valores, como proyecto concreto, es ya el ejercicio de autoconstitución, cuya memoria histórica le permite situarse en la fragilidad mundana que obliga a instancias específicas para enfrentarlo, en cada caso, como el

${ }^{18}$ Ferrara ve el proyecto de identidad social relacionado con la Eudaimonia de Aristóteles. Carlos Thiebaut lo ve relacionado con la filosofía de la acción en Cabe Aristóteles, Ed. La Balsa de Medusa, Madrid, 1989. 
proyecto de vida mejorable, como el compromiso inequívoco de saberla vivir como el reto continuo.

\section{BIBLIOGRAFÍA}

Ferrara, A., «On phrónesis», Praxis International. 7:3’4, Invierno de 1987-88.

-, «A critic of Haberma's consensual theory», Praxis International.

Habermas, J., La reconstrucción del materialismo histórico, Ed. Taurus, Madrid, 1983.

-, Teoría y praxis, Ed. Tecnos, 1988.

-, La Teoría de la Acción Comunicativa, Ed. Taurus, Madrid, 1988.

-, Escritos políticos, Ed. Península, Barcelona, 1987.

-, «Acerca del uso ético, pragmático y moral de la razón práctica», conferencia leída en México en el simposium Habermas, en 1989.

-, «Soberanía popular como procedimiento», conferencia leída en México en la Escuela de Medicina, 1989.

Taylor, Charles, Sources of the Self. The making of Modern Identity, Harvard University Press. Massachusetts, 1989.

Thiebaut, Carlos, Cabe Aristóteles, ed. La Balsa de Medusa, Madrid, 1989.

-, El arte del nombrar, próxima publicación en La Balsa de Medusa.

Toulmin, Stephen, On human understanding, trad. en Alianza Universidad, Madrid, 1979. 